RELATO DE CASOS

\title{
Linfangioma Perineal: Relato de Caso
}

\author{
Perineal Lymphangioma: A Case Report
}

\author{
ALLINE MACIEL PINHEIRO BORGES ${ }^{1}$; FLÁVIA BALSAMO ${ }^{2}$; JULIANA MAGALHÃES LOPES ${ }^{1}$; RODRIGO BRITTODE \\ CARVALHO $^{1}$; ANDRÉ LUIGI PINCINATO $^{\prime}$; GALDINO JOSÉ SITONIOFORMIGA ${ }^{3}$ \\ ${ }^{1}$ Residentes do Serviço de Coloproctologia do Hospital Heliópolis- São Paulo, S.P; ${ }^{2}$ Assistente do Serviço de \\ Coloproctologia do Hospital Heliópolis- São Paulo, S.P., TSBCP; ${ }^{3}$ Chefe do Serviço de Coloproctologia do Hospital \\ Heliópolis- São Paulo, S.P., TSBCP.
}

\begin{abstract}
BORGES AMP; BALSAMO F; LOPES JM; CARVALHO RB; PINCINATO AL; FORMIGA GJS. Linfangioma Perineal: Relato de Caso. Rev bras Coloproct, 2008;28(2): 234-237.

RESUMO: O linfangioma é uma neoplasia benigna que pode se manifestar em qualquer local do corpo, sendo a localização perineal ou retrorretal bastante incomuns. Apresenta sintomatologia inespecífica, podendo manifestar-se de diversas formas, como o abaulamento perineal e compressão de estruturas pélvicas. Relata-se um caso de linfangioma perineal com ênfase em seu tratamento já que esta entidade clínica, apesar de benigna, tem potencial de malignização.
\end{abstract}

Descritores: linfangioma, higroma, tumores, neoplasias, malformações.

\section{INTRODUÇÃO}

O linfangioma é uma neoplasia bastante incomum no períneo, havendo alguns casos relatados no espaço retrorretal. Trata-se de uma malformação vascular de baixo fluxo do sistema linfático, podendo ser localizado ou difuso, microcístico, macrocístico (também chamado de higroma cístico) ou misto. ${ }^{1}$

A literatura limita-se a poucos relatos de casos, e somente estudos maiores têm conseguido proporcionar uma estimativa da incidência global desses tumores na pelve. ${ }^{2}$

O objetivo deste trabalho é relatar um caso de linfangioma perineal e o tratamento cirúrgico.

\section{RELATO DO CASO}

JPM, 56 anos, masculino, branco, aposentado, natural de São Geraldo-MG e procedente de São Paulo-SP. Há quatro meses com abaulamento entre a bolsa escrotal e a nádega direita, associado a desconforto local. Apresentava antecedente de hipertensão arterial, em uso de hidroclorotiazida $25 \mathrm{mg}$ e amilorida $2,5 \mathrm{mg}$ por dia. Foi tabagista por 10 anos (24 cigarros/dia), tendo parado há 35 anos.

Ao exame físico geral não apresentava alterações e ao exame proctológico, evidenciava-se abaulamento da região perineal ântero-lateral direita, sem orifícios fistulosos, sinais flogísticos ou lesões de pele. A palpação local revelava tumoração de consistência amolecida, indolor, medindo aproximadamente $8 \mathrm{~cm}$ de diâmetro. A retossigmoidoscopia foi realizada até 10 $\mathrm{cm}$, sem alterações, não progredindo por dor.

$\mathrm{O}$ enema opaco mostrou livre progressão do contraste até o ceco, sem falhas de enchimento. A ultrasonografia de partes moles evidenciou um nódulo sólido, encapsulado, de limites bem definidos, pobremente vascularizado, medindo cerca de $6,8 \times 3,8 \mathrm{~cm}$ em região perineal direita, com textura de gordura. A tomografia computadorizada (TC) de pelve revelou lesão perineal hipodensa junto ao reto, porém com plano de clivagem (figura 1).

Foi submetido à exérese do tumor por via perineal com incisão arciforme a $2 \mathrm{~cm}$ da borda anal

Trabalho realizado no Serviço de Coloproctologia do Hospital Heliópolis, São Paulo, SP.

Recebido em 13/12/2007

Aceito para publicação em 01/02/2008 
desde o períneo anterior até próximo da região coccígea (10 cm de extensão), com realização de sutura primária por planos e utilização de dreno laminar na loja para drenagem de sangue (figuras 2 e 3 ). $\mathrm{O}$ dreno foi retirado na manhã seguinte com a ferida seca. $\mathrm{O}$ paciente recebeu alta hospitalar no primeiro dia do pós-operatório.

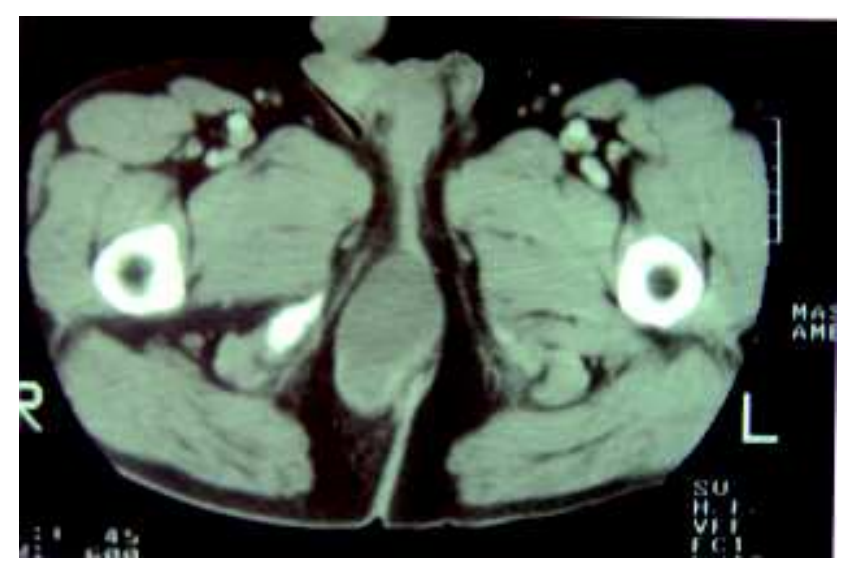

Figura 1 - TC de pelve.

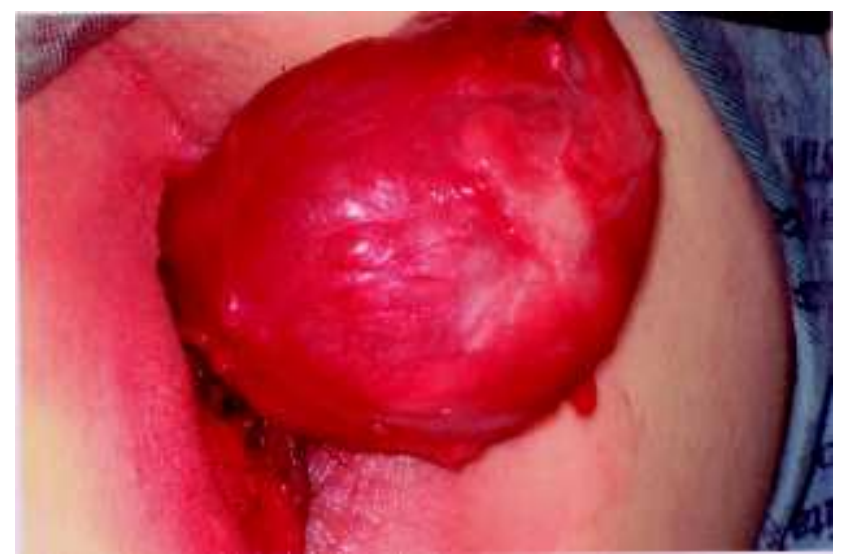

Figura 2-Ressecção do tumor.

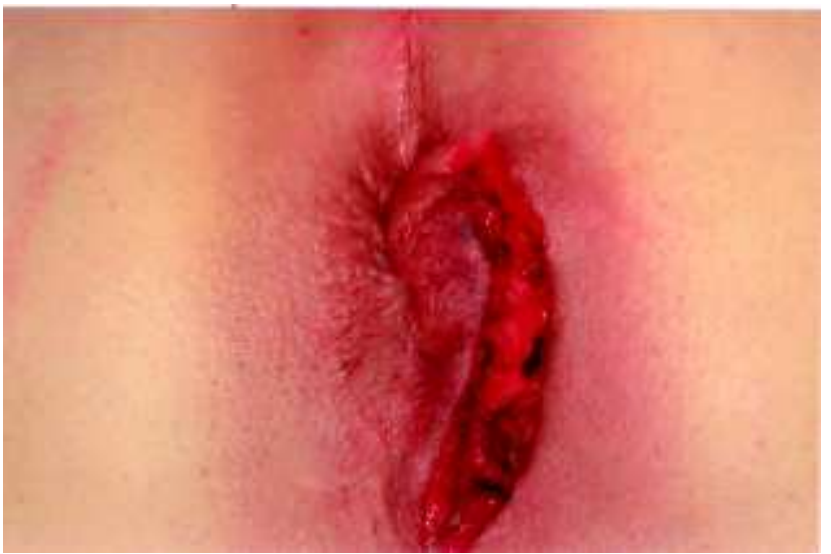

Figura 3 - Aspecto após retirada da peça.
O exame anátomo-patológico (figura 4) associado com imuno-histoquímica (figura 5) confirmou o diagnóstico de linfangioma (CD34 positivo).

Encontra-se assintomático após um ano do tratamento cirúrgico.

\section{DISCUSSÃO}

O linfangioma macrocístico ou higroma cístico é assim definido quando contém espaços císticos maiores de $2 \mathrm{~cm}^{3}$. É mais comumente encontrado no pescoço, axila, tórax, mediastino, região inguinal, e em sua maioria, diagnosticado antes dos dois anos de idade. Pode ser solitário ou multifocal, persistente, de crescimento lento ou raramente involuir, além de infiltrar ou comprimir estruturas vitais adjacentes durante episódios de hemorragia intralesional ou super infecção. ${ }^{3}$

O tipo microcístico é mais comum, contém cavidades menores de $2 \mathrm{~cm}^{3}$ e ocorre no pescoço, ombro, região proximal dos membros e períneo, sendo

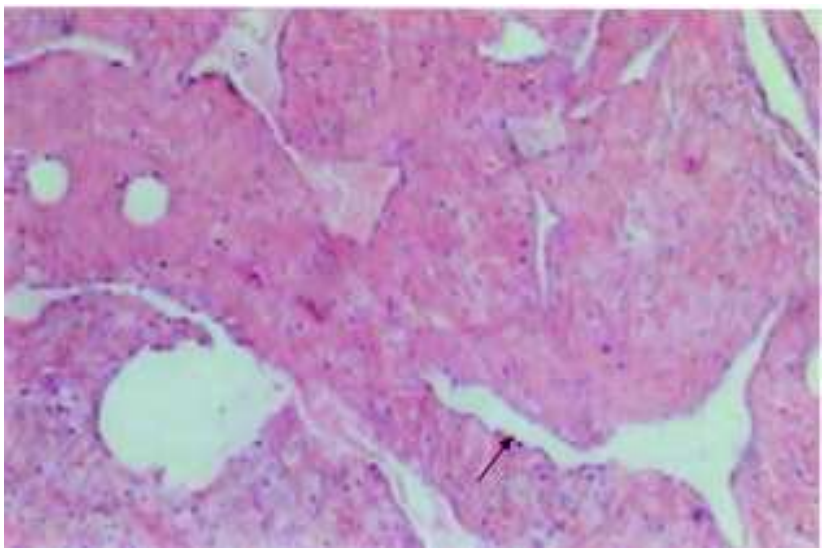

Figura 4 - Anátomo- patológico (400X).

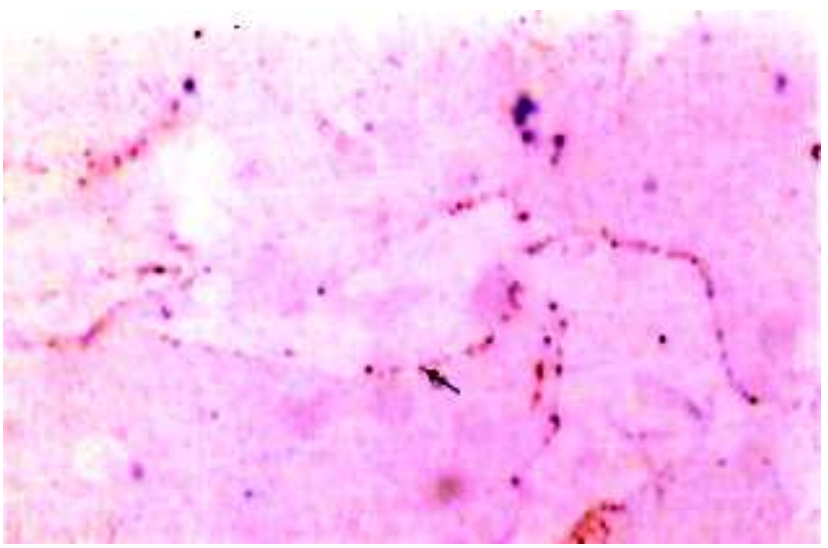

Figura 5 - Imuno-histoquímica (400X). 
diagnosticado ao final da infância. Podem ser solitários ou multifocais, bem circunscritos ou infiltrativos. ${ }^{3}$

A sintomatologia é inespecífica e pode apresentar-se como abaulamento, depressão e deformidade da região pré-coccígea, sacral ou perineal, bem como compressão de estruturas pélvicas ou ainda por complicações como abscessos retrorretais recorrentes e fístulas. ${ }^{4,5}$ As anormalidades linfáticas no trato gastrointestinal podem causar hipoalbuminemia como consequiência de enteropatia crônica perdedora de proteína. As duas principais complicações do linfangioma são sangramento intralesional e infecção. ${ }^{1}$

O diagnóstico é feito através da história clínica, exame físico e exames complementares como TC, ressonância nuclear magnética (RNM), ultra-sonografia transretal (USG), mas principalmente com a anatomia patológica e imuno-histoquímica. ${ }^{6}$

A documentação radiológica é realizada melhor pela RNM, embora o USG seja um agente auxiliar útil na confirmação da presença de linfangioma macrocístico. Apresenta-se com hipersinal em T2. As lesões microcísticas têm sinal intermediário em T1 e intermediário/alto em T2. ${ }^{1}$

Alguns estudos afirmam que a lesão não deve ser biopsiada tanto pelo risco de infecção como pela disseminação tumoral, caso seja de natureza maligna. ${ }^{2}$

O linfangioma tem aparência histológica variada com dilatações multicísticas dos canais linfáticos e espaços separados por septos fibrosos, que são desconectados dos vasos linfáticos normais. As paredes são revestidas por células endoteliais e podem ter musculatura lisa de espessura variável em sua camada externa. Em seu lúmen pode haver linfa, material protéico ou eritrócitos, semelhante às malformações venosas. $^{3}$

$\mathrm{O}$ achado de imuno-histoquímica mais comum é a positividade para os marcadores CD31 e CD34. ${ }^{7}$

Recentemente foi desenvolvido o marcador D2-40, um anticorpo monoclonal contra o antígeno M2A e é altamente específico para o endotélio linfático e negativo para o endotélio normal ou malformações venosas, arteriais ou capilares. ${ }^{3}$

As duas estratégias para tratamento das anormalidades linfáticas são escleroterapia e ressecção cirúrgica. A escleroterapia visa à obliteração luminal do linfático pela destruição endotelial com subsequiente fibrose. O etanol é considerado o agente esclerosante mais efetivo, porém a injeção é dolorosa, requerendo anestesia/analgesia. Os principais efeitos colaterais são: necrose e neuropatia locais. A absorção sistêmica pode causar arritmia cardíaca, vasoconstricção pulmonar ou hipotensão sistêmica. Outro agente esclerosante é o Ethibloc $^{\circledR}$, uma solução de etanol, aminoácidos e agente de contraste e que tem eficácia variando entre 20 $65 \%$. Outra opção é o $\mathrm{OK}-432$, uma preparação liofilizada derivada do Streptococcs pyogenes, que induz a resposta inflamatória local intensa com fibrose e tem demonstrado sucesso (60-100\% de resposta). ${ }^{1}$ Não fizemos opção pela tentativa de escleroterapia por não conhecer a natureza da lesão no pré-operatório, e também por se tratar de lesão grande para a realização deste procedimento.

Embora a maior parte dos linfangiomas nos adultos seja assintomática e benigna, recomenda-se que sejam ressecados pelo potencial de malignidade com o decorrer do tempo ${ }^{4}$, conduta por nós escolhida pela mesma razão.

Além disso, a ressecção cirúrgica é o único caminho para a cura potencial do linfangioma. ${ }^{8} \mathrm{~A}$ excisão parcial pode ser realizada, mas o cirurgião deve sempre vislumbrar a excisão total, a qual, na maioria das vezes é factível. ${ }^{1}$ Isto também foi possível em nosso caso. Em cada ressecção, há necessidade de focalizar a região anatômica afetada, bem como seus limites vasculares e estar preparado para tempo cirúrgico prolongado. ${ }^{1}$ A recorrência descrita é $40 \%$ para excisão incompleta e 17\% para excisão completa macroscopicamente. ${ }^{1}$

No caso relatado, a ressecção foi completa macroscopicamente, mas o seguimento de 12 meses ainda é insuficiente para determinarmos recidiva. 


\section{REFERÊNCIAS}

1. Christison-Lagay ER, Fishman SJ. Vascular Anormalies. Surg Clin N Am 2006; 86: 393 - 425.

2. Hobson KG, Ghaemmaghami V, Roe JP, et al. Tumors of the Retrorectal Space Dis Colon Rectum 2005; 48: 1964 - 1974.

3. Legienh GM, Heran MKS. Classification, Diagnosis and Interventional Radiologic Management of Vascular Malformations. Orthop Clin N Am 2006; 37: 435 - 474.

4. Wolpert A, Beer-Gabel M, Lifschitz O, et al. The management of presacral masses in the adult. Tec coloproctol 2002; 6:43 49.

5. Habr-Gama A, Vieira MJF, Marchan JÁ, et al. Retrorrectal Tumors in Adults. A report of five cases. ABCD Arq Bras Cir Digestive 1986; 1 (3): 71 - 78 .

6. Glasgow SC, Birnbaum EH, Lowney JK, et al. Retrorectal Tumors: A diagnostic and Therapeutic Chalenge. Dis Colon Rectum 2005; 48: 1581 - 1587.
7. Miettinen M, Blay JY, Kinblom LG, Sobin LH. In: Hamilton SR, Daltonen LA, editors. World Health Organization Classification of Tumours. Pathology and Genetics of Tumour of the Digestive System. Lyon: IARC Press; 2000. p142.

8. Ludwing KA, Kalady MF. Trans- Sacral Approaches for Presacral Cyst/Rectal Tumors. In: Operative techniques in General Surgery.Elsevier Inc; 2005. p 126-136.

\section{Endereço para correspondência:}

FLÁVIA BALSAMO

Serviço de Coloproctologia do Hospital Heliópolis

R. Cônego Xavier, 276- Vila Heliópolis

04231-030- São Paulo, S.P.

Fone: 11- 2274-7600 (ramal 244)

Fax: 11- 22747646

E-mail: flabal@uol.com.br 